\title{
Research and Simulation of Parking Resource Sharing Mode in Old Community-Taking Yingmenkou Community as an Example
}

\author{
Luxi Lu \\ Southwest Minzu University, Chengdu, China \\ Email:215219383@qq.com
}

How to cite this paper: Lu, L.X. (2020) Research and Simulation of Parking Resource Sharing Mode in Old Community-Taking Yingmenkou Community as an Example. Open Journal of Civil Engineering, 10, 250-258.

https://doi.org/10.4236/ojce.2020.103021

Received: August 23, 2020

Accepted: September 8, 2020

Published: September 11, 2020

Copyright $\odot 2020$ by author(s) and Scientific Research Publishing Inc. This work is licensed under the Creative Commons Attribution International License (CC BY 4.0).

http://creativecommons.org/licenses/by/4.0/

\begin{abstract}
In recent years, the number of permanent residents in Chengdu, Sichuan Province, China has continued to grow, and the number of private cars keeps rising. A series of problems caused by difficult parking and random parking in old communities are common. This paper will take the parking problem of the old community in Yingmenkou community, Chengdu, China as an example to summarize the current situation and parking problems of the private car parking facilities in these old communities. Based on Chengdu's current old community parking management policy, parking facility renovation and expansion policy, this paper researches and establishes a parking resource sharing model suitable for old communities. The simulation results show that this model has a small footprint and is easy to install and disassemble. It can be freely spliced and combined units according to the size of the old community and the needs of residents. It is suitable for old communities with no centralized parking lot and high parking demand by residents.
\end{abstract}

\section{Keywords}

Old Community, Parking Resource Sharing Mode, Simulation and Research

\section{Introduction}

According to the announcement of the Chengdu Bureau of Statistics on the main population data of Chengdu in 2018, the permanent population of Chengdu was 16.33 million in 2018, of which 11.9405 million were urban residents [1]. At the same time, AutoNavi Map, together with the Scientific Research Institute of the Ministry of Transport and Alibaba Cloud, released the "the traffic Analysis Report of Major Cities in China in 2017" [2]. In terms of car own- 
ership, as of December 2017, the car ownership in 53 cities across the country exceeded one million. In terms of the number of motor vehicles, Chengdu ranked second in China with the number of motor vehicle PARC of 4.52 million, second only to Beijing with 5.64 million. Against the backdrop of a growing population and motor vehicle ownership, the need for parking is growing, however, when the old communities were being built, due to the low number of motor vehicles at that time, most of the ground parking spaces in the communities were less configured and no underground parking facilities were designed. Nowadays, the problem of "difficult parking" in old communities has become more and more prominent. Therefore, solving the basic needs of parking during rush hours and daily parking of old communities is the root cause of solving the problem of "difficult parking".

The aim of this study is to conclude and summarize the current situation and parking problems of the old parking facilities in Yingmenkou community, and learn from the successful experience of parking resource sharing model, explore the application of the parking resource sharing model in the Yingmenkou community, and even the old communities in Chengdu, and explore possible solutions to the "parking difficulty" problem of old communities.

\section{Existing Problems, Research Motivation and Significance}

Yingmenkou Community is located outside the Second Ring Road, northwest of Yingmenkou Overpass. It is bounded on the east by the north section of the Second Ring Road and the neighborhood Committee of Yin Sha Road Community of Yingmenkou Street, on the south by Yingmenkou Road, on the west by Huazhao Neighborhood Committee of Yingmenkou Street, and on the north by Huazhaobi Street. The total area of the community is about 0.4 square kilometers. In charge of 21 residential yards, there are 83 residential buildings, a total of about 4600 households, and a total population of about 12,488 people, of which 10,684 are permanent residents. There are many residential courtyards in the Yingmenkou community, which belong to the residential communities built in the 1980s and 1990s. In terms of parking resources allocation, they are facing severe problems at present. For example, Yard no. 9, Yard no. 11, Yard No. 13, Yard No. 15, and Yard No. 17 of Yinshaheng Street were all built in the early 1990s. All these courtyards were built in the early 1990s with brick-concrete structures, no underground parking garages, no supporting parking spaces on the ground, or insufficient ground parking spaces (Figure 1).
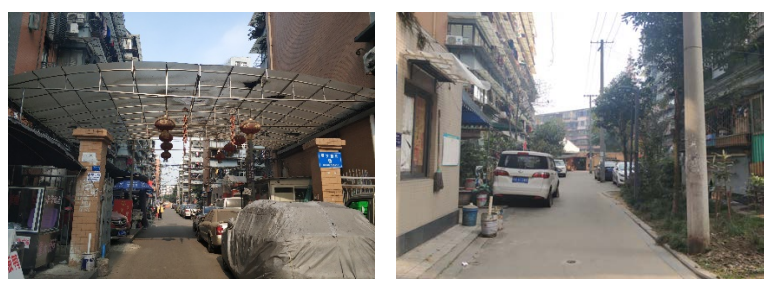

Figure 1 . Taken by the author. 
The specific forms of the "difficult parking" problem can be divided into the following types according to the actual conditions of different communities. First, the old community itself occupies a small area and there is very little floor space available. There are no ground parking spaces in the community, and only external parking spaces can be used to solve the parking problem. It is difficult to renovate and expand parking spaces in such communities, and the investment cost is high. Second, the old courtyards are equipped with ground parking Spaces inside, but the available parking Spaces cannot meet the parking needs of residents, and there is not enough spare space inside the community to increase the parking facilities. Such communities can only solve the parking problem through the exterior of the community. Third, part of the old communities have certain courtyards, but most of them are set up as community green space facilities and fire passages. The green supporting facilities can be modified such as reducing the green area to increase the number of parking spaces, but most of these old village green area is not much, and reducing the greening area through the above methods will affect the comfort and greening rate in the community. When facing the "difficult parking" problem mentioned above, the residents of old communities mostly voluntarily choose to occupy the internal roads, green belts, and fire passages in the community as parking points in order to solve the urgent parking demand, more than that, parking vehicles in nearby neighborhoods, or on public roads outside the neighborhood. As a result, on the basis of the problem of "difficult parking", it will undoubtedly bring the occupation of fire passages the city management, resulting in potential safety hazards; occupying other people's parking facilities; causing traffic congestion; causing a series of problems such as theft, which is a series of problems for urban traffic. Governance and security governance have brought huge difficulties.

Nevertheless, at this stage, for the problem of "difficult parking" in old communities, Yingmenkou community implements the unified measures adopted by Chengdu City. The main measures taken by Chengdu city are to radiate or cover the surrounding old communities as much as possible by increasing the parking allocation index in the process of old city reconstruction; Under the condition of not affecting the traffic, roadside parking can also be adopted to reduce the number of parking in the yard and alleviate the parking problem of residents. However, the traditional improvement methods mentioned above cannot properly solve the parking problems faced by such communities, such as the old ones with less greening configuration within the community and the old ones with narrow roads, large traffic flow and easy to cause congestion. In summary, most of the old communities in Yingmenkou community and even in Chengdu are small in size, dense in population, and high in the number of residents' motor vehicles. Therefore, in addition to the original improvement mode, more feasible improvement modes should be explored to further alleviate and solve the "parking difficulty" problem in the old communities. The research purpose of this paper is to establish a model of parking resource sharing mode, and explore 
a mode that has a small footprint, can be installed in a small site, and can be installed and disassembled flexibly, parking and picking up the car is easy, and at the same time, it can efficiently solve the parking problem to provide guidelines for parking design in old communities.

\section{Methodology}

\subsection{Analyze the Case of Multi-Story Car Park Building Sharing Mode}

Many scholars have studied the parking management mode of old communities regarding the difficulty of parking in old communities. Peng Ruobing [3] comprehensively introduced domestic and foreign parking difficulties in residential areas. At this stage, studies on parking resource sharing mode include Singapore Multi-storey Car Park (MSCP) [4] parking mode and American parking models.

About $80 \%$ of the population in Singapore lives in government-provided housing. In urban construction in the 1980s, Singapore's private car ownership was not high at that time, and the growth rate of private car ownership estimated in urban construction and architectural design was lower than the actual development trend, It just encloses an open space in each building group or the distance between the front and rear buildings, in which set aside one-way driveway, with a white line to draw 10 - 30 parking Spaces. However, the rapidly increasing number of private cars has a great impact on the community, causing traffic jams and disorderly parking. MSCP has been adopted by the government to address these problems in the construction of new residential areas and renovation of old towns. Multi-storey parking structures (MSCP) are generally located in the "corners" of residential land, such as the large shadow areas of high-rise buildings, long and narrow sections of north-south direction [5]. The plane form of MSCP is relatively "regular", which is a simple rectangular layout with five floors. The driveway leads to the roof, and the roof layer can also be used as a parking space. In the layout form, $7.5 \mathrm{~m}$ is used as the base modulus of the column, while in the direction of the short axis, there is a fixed depth $(16 \mathrm{~m}+2 \mathrm{~m}+$ $16 \mathrm{~m}$ ) design. Two rows of parking Spaces are arranged in the $16 \mathrm{~m}$ width on both sides, and a $6 \mathrm{~m}$ wide driveway is set between the parking Spaces. Along the direction of the long axis, there is an isolation belt of $2 \mathrm{~cm}$ "open"-the whole building is divided into two, divided into two half-storey buildings with a height difference between each other and presents a block with a staggered layout. In addition, MSCP has uniform lighting and smooth ventilation. The $2 \mathrm{~m}$ wide opening in the middle is similar to the patio inside the building, through which natural light can enter the interior, forming a natural lighting belt and ventilation belt. The exterior facade is very transparent and open, and the combination of the interior "patio" and the open exterior facade speeds up the exhaust elimination of the interior cars and makes the ventilation effect better.

The management mode of MSCP is centralized management. It is equipped with convenient service facilities such as car wash spaces and parking spaces, 
unified property management, and suction devices inside. The partial pavement of the parking lot is equipped with polymer materials that are easy to clean and scrub. MSCP can effectively "organize" the pollution of oil, exhaust, and noise in a unified way.

\subsection{Establish a Basic Model of Parking Resource Sharing Mode}

The basic unit of the parking resource sharing model established in this study is an inverted L-shaped unit (Figure 2). The basic unit is composed of $1-7$ sub-components (Figure 3). In the Figure: 1) Solar panels 2) Roof greening 3) Steel structure support members 4) Vehicle panels 5) Control bearing (control device) 6) Vertical greening 7) Sliding track.

The parking resource sharing device is intended to solve the problems of parking difficulties and insufficient parking spaces in old communities while increasing the greening rate, which is a simulation of the parking resource sharing mode. It mainly consists of steel structure system as structural components, supporting roof and vertical greening components. The solar panel 1 on the top of the roof can be connected to the battery pack in the control bearing 5 through a signal line, and the battery pack supplies power to the control bearing to make it run. After the operation of the control bearing, the vehicle plate slides along the sliding track 7 , and the vehicle plate protrudes forward for people to park and pick up the vehicle (Figure 4). The vertical greening set on the side or back can increase the greening area of about 16 square meters per standard unit. Vertical afforestation can be selected according to needs. There are two types: full-area vertical afforestation and combination of photovoltaic panels and green planting slots. The floor space of each standard unit is small, which is equivalent to the floor parking space. The length and width of the bottom car board are $5000 \mathrm{~mm} \times 2000 \mathrm{~mm}$ (Figure 5).

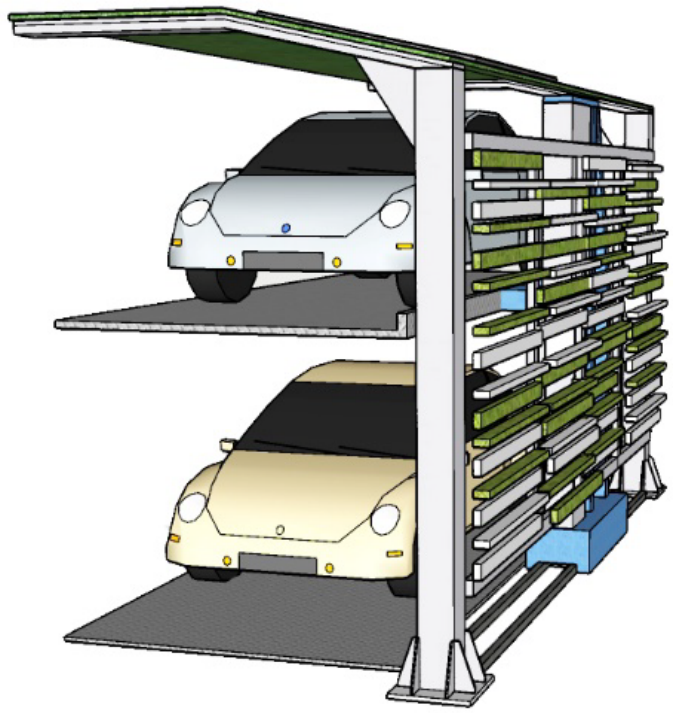

Figure 2. Painted by the author. 


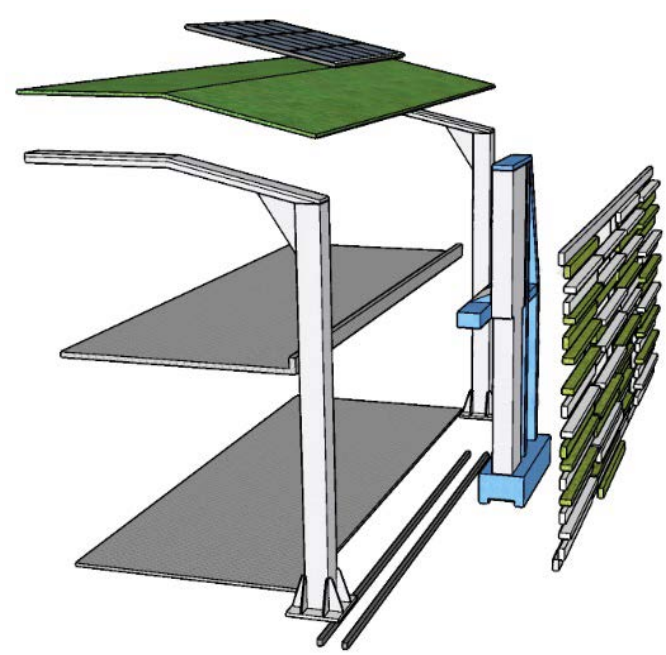

Figure 3. Painted by the author.

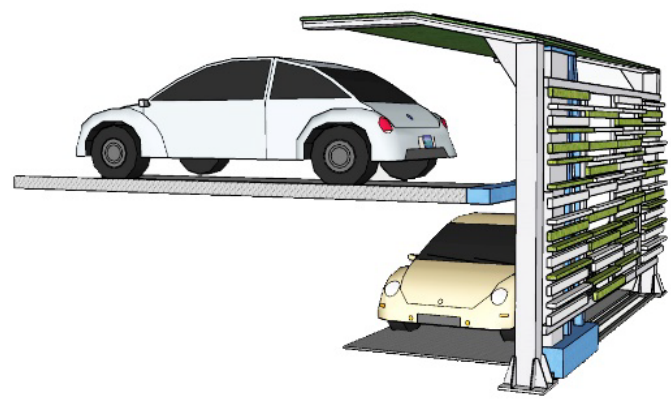

Figure 4. Painted by the author.
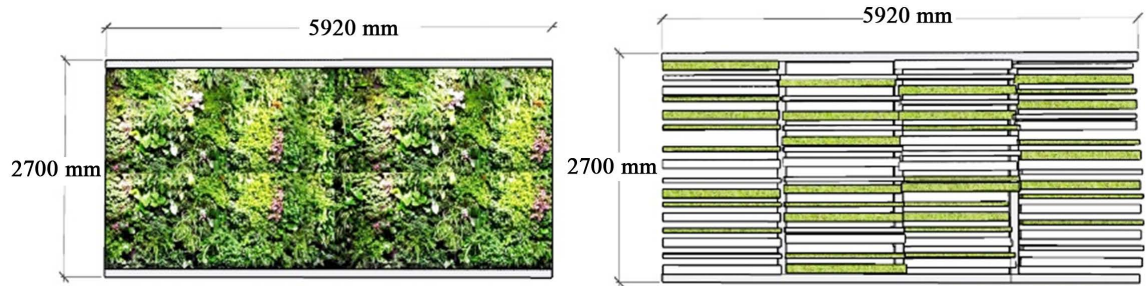

Figure 5. Painted by the author.

\subsection{Set up and Install Parking Resource Sharing Models in Old Communities}

A community, as a social life community composed of people living in a certain geographical range, has a certain geographical area; Have a certain number of people; There is a common sense and interest among the inhabitants; Has a close social interaction. In the same community, the parking situation and parking problems faced by people are more similar. Therefore, it is easier to solve the problems of the community through the same organization of the community, coordination of land use, and management of shared parking resources by taking the street communities under the administrative region as the main body, choosing sites and setting up parking resource sharing devices. 
The site selection principle of the parking resource sharing device is as follows: first, the free space in the old community is more than 10 square meters, which can be installed and set up; second, the ground parking space with ground parking area is set up; third, the public area is set up in the public square of the community at the Yingmenkou community. According to the size of the site selected, the combination unit can be assembled freely to meet the site conditions and parking requirements of the service area. The splicing units used for the size and shape of the venue can form a "Y" shape (Figure 6), a "W" shape (Figure 7 ), multiple combination types, etc. The two combination forms of " $Y$ " and "W" are composed of inverted " $L$ "-shaped foundation units. The principles of setting the combined unit are as follows: 1) The site is small, and only one or two splicing units are allowed to use basic units or "Y"-shaped units; 2) For the parking lot with narrow width but very long and narrow, "Y" shaped units can be combined back and forth to form multiple "Y" shaped combined units; 3) When the site is wider and the dimensions in both the length and width directions are larger, the "W"-shaped unit and the front and back splicing unit of the "W" unit can be used. 4) When the site is narrow, but the parking demand is large, the height of the unit and the number of load plates can be increased.

This model adopts a prefabricated steel structure support system, which can be splicing and adding or subtracting units according to requirements. When the site of the later selected site has other functional requirements, such as the demolition of nearby old communities, site acquisition and community public greening, or the reduction in parking demand, the increase in demand, etc., it can be demolished and moved to areas of increased demand for use. It can not only change the ration according to actual needs, but also can be flexibly installed and dismantled.

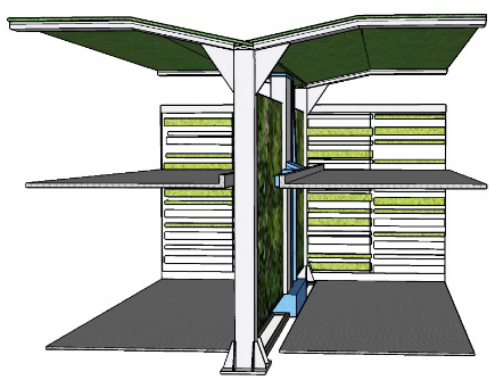

Figure 6. Painted by the author.

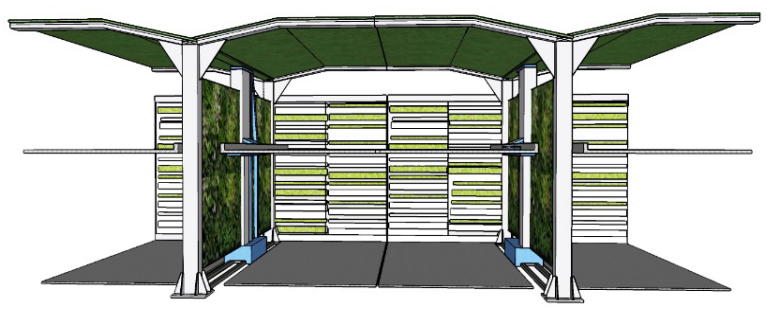

Figure 7. Painted by the author. 


\subsection{Formulate the Use and Management Strategy of Parking Resource Sharing Model}

The community should coordinate the following situations in the management of parking resource sharing mode, the first is to count the existing parking spaces in the old quarters of this community and incorporate them into the network management system. The second is to use the motor vehicle travel distribution method and borrow the motor vehicle travel distribution formula to calculate the peak and trough periods of parking demand in the old community, and analyze the number of parking facilities gap in the peak or regular hours of parking facilities in the old community by using the characteristic indexes of parking facilities. For example, the peak occupancy period of parking spaces in public land near old communities is after 6:00 pm, nighttime is the peak time for parking, which is the opposite of commuting time and parking demand in public offices. At the same time, it is worth noting that the parking demand of residents also involves weekends and restricted traffic periods. The third is to carry out quantitative statistical analysis of parking demand based on the above strategy, calculate the demand for parking spaces in this community, and select the location according to the demand and install the parking resource sharing model of the corresponding scale and number. At the same time, through this, the sensors assembled in the model are automatically connected to the data application terminal. Residents can select parking locations and manage their vehicles according to the vacant locations and numbers displayed on the data application.

\section{The Result of Simulation Parking Sharing Mode}

According to the analysis of the appeal, the model of this kind of parking resource sharing model has a small area, each basic unit occupies only 10 square meters, and can use a very narrow open space with a width greater than 2 meters. It can be used on the same area because it can be flexible. Assembled to 2 or 3 floors or more, so 2 to 3 times more vehicles can be parked. At the same time, the green area is increased. A basic model unit can increase the green area by about 16 square meters. Therefore, it meets the needs of residential parking spaces and public green space and recreational space, and solves the contradiction of occupying open space and green space in old communities. It is easy to operate and use. Through the splicing of a basic model unit, it can be spliced into a variety of combination modes such as " $\mathrm{Y}$ " or " $\mathrm{M}$ " as required, which is easy to be accepted by residents of old communities. At the same time, the cost is small. Parking fees can be used to manage this kind of public parking resources, and the integrated governance will be effective. Compared with the renovation and expansion of parking facilities, the parking resource sharing mode can use parking space more flexibly. When providing more and more complete parking spaces, the flexible demand for parking land and the advantages of sustainable use of shared parking land obviously. 


\section{Conclusion}

This paper sorts out the parking status and problems of old communities and finds that due to the age of construction, failure to include the number of private cars in the planning and construction and provide them with sufficient parking spaces is the essential problem of the "difficult parking" phenomenon in old communities. This has caused a series of problems such as traffic congestion, occupation of fire passages, theft, etc. It is urgent to choose practical measures to tackle the parking problems closely related to the residents of old communities. However, the development of the parking resource sharing model of old communities in Chengdu is still in its infancy. Therefore, this article regards the parking problem of old communities in the city as a part of the construction of a smart city by paying attention to parking problems in old communities, analyzing the main reasons leading to parking problems, exploring and establishing a parking resource sharing model suitable for old communities, and providing some methods and suggestions for parking management problems in old communities.

\section{Conflicts of Interest}

The author declares no conflicts of interest regarding the publication of this paper.

\section{References}

[1] Chengdu Bureau of Statistics (2019) Announcement of Chengdu Bureau of Statistics on the Main Population Data of Chengdu in 2018.

[2] (2018) 2017 China's Major Cities Traffic Analysis Report Released. Urban Planning Newsletter, No. 3, 14.

[3] Peng, R.B. (2018) Research on “Difficult Parking” in Wuhan's Old Community Based on Multi-Center Governance. Central China Normal University, Wuhan.

[4] Zhao, S.L., Zhou, Y.L. and Lou, S.J. (2012) Discussion on MCP Parking Methods in Singapore. Housing Technology, 32, 12-16.

[5] Cheng, J. and Yang, L. (2002) A Preliminary Study on the Form of Parking in Urban Residential Areas: Lessons from Singapore MSCP. Urban Development, No. 4, 34-35. 